Lepr. Rev. (1969) 40, 93-98

\title{
Epidemiological Studies in Leprosy in Gudiyatham Taluk \\ II. Patterns of Familial Aggregation of Leprosy in an Endemic Area*
}

\author{
P. S. S. RAO \\ Consultant Biostatistician \\ A. B. A. KARAT $\dagger$ \\ Consultant Physician \\ Mr's. S. KARAT \\ Consultant Surgeon \\ Schieffelin Leprosy Research Sanatorium, Karigiri, Tamilnadu, S. India
}

\begin{abstract}
A study of over 38,000 families living in the Gudiyatham Taluk, S. India, revealed 3200 families in which there was at least one case of leprosy and that in 490 of these families there was more than one case. The many interesting findings, which are presented in the 13 tables, cannot be effectively summarized but it may be noted that 2 patients in the same family of ten suffered from different types of leprosy and also that the disease in a parent was not always of the same type as that in an affected child. Further, out of 67 families in which both parents had some form of leprosy, only in 20 of them were the children affected.
\end{abstract}

\section{INTRODUCTION}

The influence of genetic inheritance in the epidemiology of disease is of considerable interest and importance for understanding the transmission and endemicity of such diseases. While it is generally accepted that Mycohacterium leprae is the causative organism in leprosy, it has been suggested that the bacillus cannot produce the disease in all human beings exposed to it, owing to a supposed variation in susceptibility. Such variation may be due to several environmental factors as well as to factors described as innate, inborn, constitutional, familial or hereditary (Spickett, 1962). Families with multiple-cases of leprosy provide good material for investigation of these types of genetic studies and several authors have reported interesting findings (Fernandez, 1948; Nordeen and Mohamed Ali, 1964; Mohamed Ali, 1965; Christian et al., 1966). Doull et al. (1942) showed in Cebu that the risk of contracting the disease was as much as 8 times

Received for publication 3 April, 1969.

*Financed by Swedish Red Cross, Stockholm, and SRS-IND-3:.

$\dagger$ Requests for reprints should be addressed to Dr. A. B. A. Karat. greater for individuals in contact with lepromatous patients, and twice as great for individuals in contact with tuberculoid patients, as it was for individuals not known to have had household contacts with leprosy patients. Lechat et al. (1968) further studied the blood group systems in this population to determine possible associations. More recently, Sharma (1968) has reported studies undertaken in Uttar Pradesh, India.

No study has so far produced conclusive evidence about household transmission of leprosy. If problems of genetics, as they affect leprosy, are to be studied the data must be collected carefully and on a world-wide scale in view of the great variations noted in the manifestations of this disease in different geographical areas. And even to make tentative hypothesis, it is necessary first to describe clearly the patterns of familial aggregation in relation to the demographic characteristics in the community. In this paper certain facts determined as part of a leprosy control programme in Gudiyatham Taluk, North Arcot District, are described and the implications discussed. 
MATERIALS AND METHODS

Data from a population of 300,000 pertaining to two-thirds of the Gudiyatham Taluk is considered in this paper. Out of the 38,158 families surveyed and examined, 3200 families contained at least one leprosy patient and in 490 of these there was more than one case of leprosy. The relative proportion of families with no patient, one patient, and multiple patients is shown in Table 1.

TABLE 1

Familial aggregation in 38,158 families studied

\begin{tabular}{cc}
\hline No. of patients & Total $(\%)$ \\
\hline 0 & 91.6 \\
1 & 7.1 \\
2 or more & 1.3 \\
Total & 100.0
\end{tabular}

The characteristics of patients in terms of age and sex are shown in Table 2 .

TABLE 2

Age and sex of patients studied

\begin{tabular}{lcc}
\hline Patients & No. & $\%$ \\
\hline Men & 1702 & 44.4 \\
Women & 1106 & 28.9 \\
Children & 1021 & 26.7 \\
Total & 3829 & 100.0 \\
\hline
\end{tabular}

In terms of type of leprosy the pattern is as presented in Table 3.

TABLE 3

Type of leprosy in the patients studied

\begin{tabular}{lrr}
\hline \multicolumn{1}{c}{ Type } & No. & $\%$ \\
\hline Lepromatous & 777 & 20.3 \\
Tuberculoid & 2348 & 61.3 \\
Borderline & 322 & 8.4 \\
Indeterminate & 382 & 10.0 \\
Total & 3829 & 100.0
\end{tabular}

In this paper the words "family" and "household" are considered synonymous, and defined as "a group of individuals partaking of food from a common kitchen". The basic characteristics of the patients, as well as salient demographic and socio-economic characteristics of the families to which these patients belonged, have been abstracted from relevant records maintained as part of the leprosy control programme. For purposes of comparison similar characteristics from families with no leprosy patient(s) have also been abstracted and used. Additional data such as pedigrees, contacts outside the household, other members of the families who might have had leprosy but were not residing at this time in the area, were obtained through sample surveys and interviews conducted by trained paramedical personnel.

\section{FINDINGS}

\section{Size of family}

The average size of families in which there was more than one patient is compared with that of families in which there was only one patient or no patient. The findings are shown in Table 4.

\begin{tabular}{lccc}
\multicolumn{3}{c}{ TABLE } & \\
Size of family & \\
\hline & $\begin{array}{c}\text { Mutiple-case } \\
\text { families }\end{array}$ & $\begin{array}{c}\text { Single-case } \\
\text { families }\end{array}$ & $\begin{array}{c}\text { General } \\
\text { population }\end{array}$ \\
\hline Average & & & \\
family size & 6.6 & 5.76 & 5.25 \\
S.D. & 2.47 & 2.52 & 2.50
\end{tabular}

It will be seen that the average family size in one-case families is significantly greater $(P<0.01)$ than that in the general population, while the average family size in multiple-case families is significantly greater $(P<0.01)$ than that in the single-case families. Another way of looking at this problem would be to determine the proportion of single-case families and the proportion of multiple-case families among all families of a particular size in the general population. Comparison of these 2 ratios in each size of family might give some indication of any associations that might exist between size of family and multiple cases of leprosy in a family. The findings are shown in Table 5.

The ratios of the percentage between single and multiple-patient families in each size of family were calculated. These show that as the family size increases the ratio changes from $5: 1$ to 3: 1, indicating thereby that as family size 
TABLE 5

Percentage of families with single or multiple cases in the general population of different family sizes

\begin{tabular}{rcc}
$\begin{array}{l}\text { Size of } \\
\text { family }\end{array}$ & $\begin{array}{c}\text { Single-case families } \\
\text { to all families }(\%)\end{array}$ & $\begin{array}{c}\text { Multiple-case families } \\
\text { to all families }(\%)\end{array}$ \\
\hline 1 to 5 & 7.2 & 1.3 \\
6 to 10 & 8.9 & 2.4 \\
11 to 15 & 13.2 & 5.3 \\
$>16$ & 25.0 & 8.3 \\
\hline
\end{tabular}

increases the number of families containing multiple-cases shows a significant rise. Of course, it should be noticed also that even among large families, single-cases are more common than multiple-cases. The number of patients per 100 families in each size of family can also be computed and the results are as shown in Table 6.

TABLE 6

Number of patients per 100 families in relation to size of family

\begin{tabular}{cr}
\hline Size of family & No. of patients per lo() families \\
\hline 1 to 5 & 9.9 \\
6 to 10 & 14.9 \\
11 to 15 & 25.4 \\
$>16$ & 41.7 \\
\hline
\end{tabular}

This also reveals the association between the aggregation and large families.

Demographic characteristics of patients belonging to single-case and multiple-case families

Sex ratio. The sex ratio (number of males per 1000 females) in the rural population belonging to Gudiyathan Taluk is 981 . The sex ratio of patients in single-case and multiple-case families are as given in Table 7 .

\begin{tabular}{lc}
\multicolumn{2}{c}{ TABLE } \\
& Sex ratio \\
\hline \multicolumn{1}{c}{ Category } & Sex ratio ( (no. of males \\
& per 1000 females $)$ \\
\hline General population & 981 \\
Single-patients & 1549 \\
Multiple-patients & 1346 \\
All patients & 1486 \\
\hline
\end{tabular}

It is a known fact that among leprosy patients there is a predominance of males. Among the single-patients this predominance is intensified, while among the multiple-patients it is less so, though there is still a greater predominance of males than in the general population.

Age distribution. The percentage distribution of patients in single-case and multiple-case families are shown in Fig. 1.

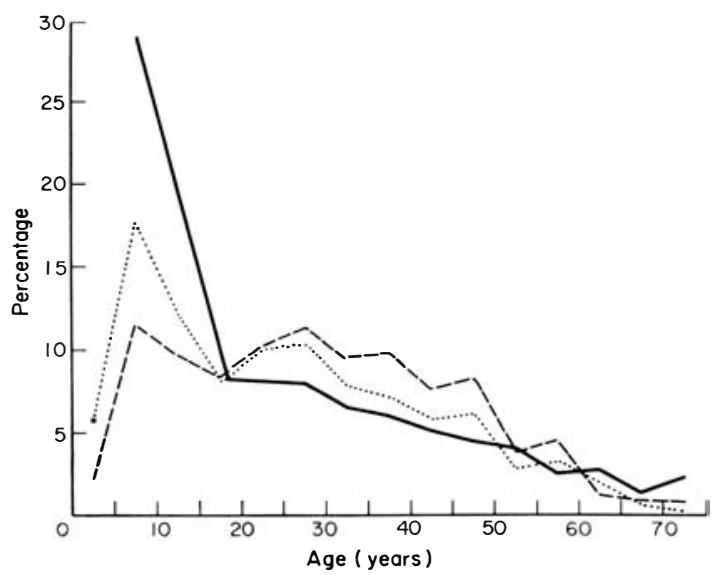

Fig. I

Age distribution of general population (- - ) compared with age distributions of patients in singlecase $(---$,$) and multiple-case (. . . . ) families.$

It is observed that patients belonging to multiple-case families are on the average of younger age than patients in single-case families; they are, however, still not as young as the general population in the area. Another way of looking at the age distribution is to see how many of the patients in each age-group are affected in the general population as a whole and belong to single-case families and to multiple-case families. These findings appear in Table 8.

TABLE 8

Prevalence of leprosy in different age groups in the general population

\begin{tabular}{cccc}
\hline $\begin{array}{c}\text { Age group } \\
(y r)\end{array}$ & $\begin{array}{c}\text { Single-case } \\
\text { family }\end{array}$ & $\begin{array}{c}\text { Multiple-case } \\
\text { family }\end{array}$ & $\begin{array}{c}\text { All-patients } \\
\text { families }\end{array}$ \\
\hline 0 to 10 & 0.61 & 0.43 & 1.04 \\
11 to 25 & 1.32 & 0.56 & 1.88 \\
26 to 45 & 1.89 & 0.63 & 2.52 \\
46 and over & 1.47 & 0.43 & 1.9 \\
\hline
\end{tabular}


It is observed that the peak-age group is between 26 and 45 years consistently in both the single-case and multiple-case family patients. In the 4 age groups the proportions of patients in single-case families are compared. While there was no significant difference among those under 10 years of age, in the higher age groups there were :3 times as many patients in the single-case families as in the multiple-case families.

Considering the prevalence of leprosy in different generations in families where this could be studied, the pattern is as shown in Table 9 for 2-patient and 3-patient families.

TABLE !)

Familial aggregation in different generations among multiple-case families

\begin{tabular}{lcc}
\hline \multicolumn{1}{c}{ General } & $\begin{array}{c}\text { Double- } \\
\text { patient } \\
\text { families }(\%)\end{array}$ & $\begin{array}{c}\text { Triple- } \\
\text { patient } \\
\text { families }(\%)\end{array}$ \\
\hline $\begin{array}{l}\text { Within the same generation } \\
\text { or between marriage }\end{array}$ & & \\
$\quad \begin{array}{l}\text { partners } \\
\text { Between two consecutive }\end{array}$ & 41.7 & 23.7 \\
$\quad \begin{array}{l}\text { generations } \\
\text { Between the first and third } \\
\quad \text { generations }\end{array}$ & 55.8 & 72.4 \\
All three-generations & 2.5 & 2.6 \\
\hline
\end{tabular}

Here again it is observed that involvement in 2 consecutive generations is the most common phenomenon. The involvement was, however, not necessarily between those having the most intimate contact. For example, where parents

TABLE 10

Familial aggregation of parents and children

No. of families

(a) No parent affected

Children affected

1180

(b) Father alone affected

No child affected

627

Children affected

132

(c) Mother alone affected

No child affected

565

Children affected

122

(d) Both parents affected

No child affected $\quad 47$

Children affected and children were studied, the pattern is as presented in Table 10 .

We see from this table that in only $10.2 \%$ of the families both parents and children are affected and in nearly $44 \%$ of families the children are affected but not the parents. From the same table, we also notice that of 171:3 couples of whom one member had leprosy, in only 67 (or $4 \%$ ) were both members affected. Further analysis is being continued.

Type of leprosy. The type of leprosy seen in patients belonging to single-case families and multiple-case families are as shown in Table 11 .

TABLE 11

Type of leprosy in single-case and multiple-case families

\begin{tabular}{lrrrr}
\hline & \multicolumn{2}{c}{ In single-case } & \multicolumn{2}{c}{ In multiple-case } \\
Classification & \multicolumn{2}{c}{ families } & \multicolumn{2}{c}{ families } \\
& No. & $\%$ & No. & $\%$ \\
\hline Lepromatous (L) & 548 & 20.2 & 229 & 20.5 \\
Tuberculoid (T) & 1672 & 61.7 & 676 & 60.4 \\
Borderline (B) & 238 & 8.8 & 84 & 7.5 \\
Indeterminate (I) & 252 & 9.3 & 130 & 11.6 \\
& & & & \\
Total & 2710 & 100.0 & 1119 & 100.0 \\
\hline
\end{tabular}

It is notable that in multiple-case families there were more cases of the indeterminate type of leprosy, whereas there was no difference in the lepromatous-type rate. Considering the multiplecases in the same family the type of leprosy seen was not the same among all those affected.

TABLE 12

\begin{tabular}{cccc}
\hline Ist & Type & No. actually & Theoretical \\
seen & & \\
\hline L & 2nd & 23 & 16 \\
L & L & 89 & 96 \\
L & T & 9 & 13 \\
L & I & 18 & 17 \\
T & T & 151 & 145 \\
T & B & 32 & 39 \\
T & I & 43 & 48 \\
B & B & 7 & 3 \\
B & I & 6 & 6 \\
I & I & 9 & 4 \\
& & 387 & 387
\end{tabular}


For example, the types of leprosy in 2-case families are as indicated in Table 12.

It is also noticed that in only $50 \%$ of the 2 -case families were both the patients suffering from the same type of leprosy. The number of cases of different varieties in $\mathbf{2}$-case families based on the prevalence of the different types of leprosy in the area has been theoretically worked out and shown in Table 12. The $\chi^{2}$ test of significance revealed that the differences between the observed and the theoretical were statistically not significant, thus indicating that there was no predominance of multiple cases in family where there was a lepromatous index case, and also that the prevalence of different combinations reflects the pattern of endemicity seen in the area.

In regard to 3-case families, the proportion of families in which all 3 patients had the same type of leprosy is much smaller $(25$ or $33 \%$ ), as shown in Table 13. This percentage declines considerably as the number of cases in a family increases to 4,5 and 6 .

TABLE 13

Type of leprosy in 3 -case families

\begin{tabular}{|c|c|c|c|}
\hline $1 s t$ & $\begin{array}{l}\text { Type } \\
\text { 2nd }\end{array}$ & $3 r d$ & No. \\
\hline $\mathrm{L}$ & $\mathrm{L}$ & $\mathrm{I}$ & 1 \\
\hline $\mathrm{T}$ & $\mathrm{T}$ & $\mathrm{T}$ & 24 \\
\hline $\mathrm{L}$ & $\mathrm{L}$ & $\mathrm{T}$ & 3 \\
\hline $\mathrm{I}$ & $\mathrm{I}$ & I & I \\
\hline $\mathrm{T}$ & $\mathrm{T}$ & $\mathrm{L}$ & 16 \\
\hline $\mathrm{T}$ & $\mathrm{T}$ & B & 3 \\
\hline $\mathrm{T}$ & $\mathrm{T}$ & I & 10 \\
\hline$B$ & B & L & 2 \\
\hline B & $\mathrm{B}$ & $\mathrm{T}$ & 1 \\
\hline I & I & $\mathrm{T}$ & 3 \\
\hline $\mathrm{L}$ & B & I & 1 \\
\hline L & $\mathrm{T}$ & I & 6 \\
\hline $\mathrm{T}$ & B & I & 2 \\
\hline Total & & & 73 \\
\hline
\end{tabular}

Socio-economic characteristics. In a sample of villages, the religion, community, and occupational patterns in the single- and multiple-case families were studied. The familial aggregation of patients was not related either to the socioeconomic groups or to the occupational patterns in these villages.

\section{COMMENTS}

The incidence of leprosy is probably dependent on a chance balance between opportunity for infection and the degree of individually existing immunity (Skinsnes, 1964). In an area where the leprosy prevalence is high and the disease has been endemic for many years it is surprising that only about $1 \%$ of the families resident in the area have multiple-patients in them. Similar findings have been shown in studies at Chingleput, Lucknow, Sholapur, and in some endemic areas of the United States of America (Sharma, 1968).

Familial aggregation could be the result of inherent susceptibility to the disease and/or intensity of contact with leprosy in the same household. Alternatively, in view of the large number of members in a household, such members might through their wider occupational or social contacts outside the household, reflect the prevalence of the disease in the area. Nordeen and Mohamed Ali (1964) and Mohamed Ali (1965) computed the average number of patients according to size of family and concluded that there was no correlation between the number of cases and size of the family. While one cannot expect a proportionate increase in the number of patients (as envisaged by these 2 authors) our study shows definitely that largeness of family and familial aggregation are associated.

From this study it appears that the index case in a family is more likely an adult male. There is, however, very little evidence to show that the secondary cases in a family acquire the disease from this index case either as a result of genetics or due to intra-familial contact. Doll and Kellock (1951) found evidence to show that relatives of gastric ulcer patients tend also to have gastric ulcer, rather than duodenal ulcer, and this appears to hold for the site of the ulcer in different generations as well as in the same generation. In the results presented here it was quite common to see polar varieties of leprosy within the same family. This might be explained as due to genetic variability in the bacillus (Spickett, 1962). It might also be explained on the basis of immunological response in the host (Skinsnes, 1964). At the same time, familial 
aggregations can also be attributed to interfamilial contact. This is an important issue, particularly in a rural population where several households or families, though housed independently, often live, work, and move together as though they all belonged to one household. It is obvious from the results that the common associations popularly assumed as intimate, such as between husbands and wives or between parents and children, have not been responsible for any large number of multiplecases within families. Such findings have also been reported through other studies (Aycock, 1941). x

Even assuming that leprosy manifests itself after a long incubation period, the pattern of prevalence of multiple-patient families seems to be as much a function of exposure to the disease outside the family as it is to exposure inside the family.

Before drawing any inference from such a finding it is essential to view this phenomenon in relation to the degree of exposure between members of the same family, the concept of prolonged and intimate contact, the acquisition of the disease from outside the household either through occupational or social contacts, inherent as opposed to acquired susceptibility, acquired or passive immunity, the rendering of the disease inactive through treatment, exacerbations of the disease, and the genetic variability in the bacterium itself.

Carefully planned longitudinal studies with reliable baseline data of the population examined, and subjected to periodic examinations, are useful for this purpose. Data on pedigree drawn for a representative random sample of families with one leprosy patient and compared with that for families showing familial aggregations are also valuable. Data acquired from control programmes are based on communities where leprosy patients are under treatment; thus open cases of leprosy are bound to be rendered noninfective in course of time. While the disease could have been transmitted before the treatment began, it is essential that the duration of the disease before the treatment was started, the status of the disease at the time of beginning treatment, as well as the duration of treatment, should all be taken into account in interpreting familial aggregations. Only studies on a worldwide basis which present facts obtained through objective and simple measurement can contribute substantially to throwing light on this crucial problem of the transmission and epidemiology of leprosy.

\section{ACKNOWLEDGMENTS}

We are grateful to $\mathrm{Mr}$. V. G. Kaliaperumal, statistician, and Mr. S. Philip, secretary, for their help in the preparation of this paper.

We should also like to place on record our deep appreciation of the financial assistance and encouragement we have received from the Swedish Red Cross, Stockholm, without which this study could not have been undertaken. This work has also been supported in part by the PL-480 grant of the Social Rehabilitation Services, Washington, under the terms of the project SRS-IND-32.

\section{REFERENCES}

AYCOCK, W. L. (1941). Familial susceptibility to leprosy. Am. J. med. Sci. $201,450$.

Christian, E. R., Shamrao, A., Christian, L. R., CHRISTIAN, J. J. and CHRISTIAN, I. v. (1966). A study of the transmission of leprosy in families. Lepr. India 38, 9 .

DOLL, R. and KELLOCK, T. D. (1951). The separate inheritance of gastric and duodenal ulcers. Ann. Eugen., Camb. 16, 231.

DOULL, J. A., GUINTO, R. S., RODRIGUEZ, J. N. and BANCROFT, H. (1942). The incidence of leprosy in Cordova and Talisay, Cebu, Philippines. Int. .J. Lepr. $10,107$.

FERNANDEZ, J. M. M. (1948). Resultados del examen de niños y conyuges convivientes con enfermos de lepra. Rev. Med. Rosario 38, 780.

LECHAT, M. F., BIAS, W. B., GUINTO, R. S., COHEN, B. H., TOlentino, J. G. and ABAlos, R. M. (1968). A study of various blood group systems in leprosy patients and controls in Cebu, Philippines. Int. .J. Lepr. 36, 17.

MOHAMED ALI, P. (1965). Genetics in leprosy. Genetic influence in leprosy. Lepr. India 37, 252.

NORDEEN, S. K. and MOHAMED ALI, P. (1964). A study of 579 families having multiple cases of leprosy; first report. Lepr. India 36, 176.

SHARMA, v. K. (1968). The epidemiological significance of leprosy within the household. Int. J. Lepr. 36, 1.

SKINSNES, O. K. (1964). Immunology in leprosy. II. The immunological spectrum of leprosy. In Leprosy in Theory and Practice, 2nd ed., p. 165. Bristol: John Wright \& Sons.

SPICKETT, s. G. (1962). Genetics and the epidemiology of leprosy. I. The incidence of leprosy. II. The form of leprosy. Lepr. Rev. 33, 76, 173. 